\title{
Construction of foundation pit monitoring information cloud platform based on SaaS mode
}

\author{
Liu Qiong*, Zeng Dongling, Ouyang Zhengping, Zhang Yinzu, Yang Yongchang, Liu Yong \\ Hainan Hydrogeological Engineering Geological Survey Institute, Haikou, Hainan Province, China
}

\begin{abstract}
With the rapid development of Internet cloud computing technology, big data and visualization and other new technologies, the powerful data storage, calculation and analysis capabilities of new technologies provide favorable conditions for improving the timeliness, reliability and informatization level of foundation pit monitoring. By using SaaS mode and cloud computing technology, this paper subdivides the requirements of foundation pit monitoring work, and puts forward solutions according to design thinking and design means. The foundation pit monitoring information cloud platform is built in the way of Cloud Architecture, which greatly improves the efficiency of foundation pit monitoring, and realizes the high sharing of monitoring data information and platform resources.
\end{abstract}

\section{INTRODUCTION}

In recent years, several fatal foundation pit collapses have been reported in China, which caused enormous casualties, property losses and damages to infrastructure such as municipal roads, tubes and wires as well as environment resources. Thinking highly of the foundation pits and sub-projects with great jeopardy, MOHURD (Ministry of Housing and Urban-Rural Development of the People's Republic of China) and State Administration of Work Safety have released rules and principles, specifications and documents to strengthen the monitoring of foundation pits. Under such circumstance, it is urgent to make the surveillance of foundation pits more effective, reliable and information-dependent.

However, due to the lack of monitoring systems of foundation pit information in Hainan province, inefficiency, impotent sharing, floppy network between the analysis and single precaution approach have all become the obstacle in development of supervision information platforms. The dramatic development in the technology of internet information, cloud computing, big data analysis and visualization provided technical support for the efficiency of foundation pit data analysis, capacity of supervision precaution and sharing of surveillance data. Therefore, it is significant in project practicing to think how to apply the internet big data and cloud computing into foundation pit information platform and realize the real-time sharing of data.

Against such a background, this paper adopted Software as a Service (short for SaaS) model and developed a surveillance system of foundation pit information cloud platform, which was based on internet cloud server and MySQL database and used load balance to achieve collaborative work under multi servers, moreover, users' demands had also been absorbed to help the analysis. Accept enjoy numerous service functions such as data upload, storage, calculation analysis and report generation, users can also look up and share the supervision data by PC and mobile phone, which provides a practical approach to make the foundation pit supervision more intelligent and information-oriented.

\section{INTRODUCTION OF SAAS MODEL}

Software as a Service (short for SaaS) is a brand-new software application model, in which users don't have to pay for the software but rent internet-based services from the provider to run business, and it is provider instead of user who is responsible to manage and maintain the software. ${ }^{[1]} \mathrm{SaaS}$ is exclusively used in and for Internet, which provides services through remote interaction, and facilitators will provide a full set of services like hardware construction, internet service, software running platform, system maintenance and data restoration. Thus, without wasting too much time in building information system, companies can achieve their goals through internet remote interaction. ${ }^{[2]}$

The differences between traditional service and SaaS are showed in Table 1. ${ }^{[3,4,5]}$ 
Table 1. Comparation between SaaS and traditional model.

\begin{tabular}{|c|c|c|}
\hline & Traditional service & SaaS \\
\hline $\begin{array}{l}\text { Hardware } \\
\text { cost }\end{array}$ & $\begin{array}{l}\text { High: pay for server and } \\
\text { storage device }\end{array}$ & $\begin{array}{c}\text { Low: only need to } \\
\text { pay when you } \\
\text { need }\end{array}$ \\
\hline $\begin{array}{l}\text { Software } \\
\text { cost }\end{array}$ & $\begin{array}{l}\text { High: need to install } \\
\text { configuration system and } \\
\text { app in computer }\end{array}$ & $\begin{array}{l}\text { Low: network } \\
\text { transmission, no } \\
\text { need to install } \\
\text { system and app }\end{array}$ \\
\hline Total cost & $\begin{array}{l}\text { High: hardware, software } \\
\text { cost in pre stage and } \\
\text { maintenance, upgrade in } \\
\text { post stage }\end{array}$ & $\begin{array}{l}\text { Low: no need to } \\
\text { install, manage } \\
\text { and upgrade } \\
\text { software }\end{array}$ \\
\hline Risk & $\begin{array}{l}\text { High: need to maintain } \\
\text { software and have no } \\
\text { restrain to provider after } \\
\text { the purchase }\end{array}$ & $\begin{array}{l}\text { Low: Provider } \\
\text { will be } \\
\text { responsible for all } \\
\text { the latent } \\
\text { technical } \\
\text { problems such as } \\
\text { data, middleware, } \\
\text { server and } \\
\text { storage, thus } \\
\text { users' risk is low }\end{array}$ \\
\hline $\begin{array}{l}\text { After-sale } \\
\text { service }\end{array}$ & $\begin{array}{l}\text { No service: There's no } \\
\text { after-sale service as soon } \\
\text { as the terminal of contract. } \\
\text { Users need to pay for the } \\
\text { extra upgrade service }\end{array}$ & $\begin{array}{l}\text { Continuous } \\
\text { service: Provider } \\
\text { will offer } \\
\text { continuous } \\
\text { service of } \\
\text { software } \\
\text { maintenance and } \\
\text { upgrade } \\
\end{array}$ \\
\hline
\end{tabular}

The advantages of SaaS have outgrown the traditional model, since the former is simple and economy-friendly, users don't need to develop, deploy and maintain application, nor responsible for the upgrade of hardware and software so that the cost can be reduced. Applications are operated in remote server and can be visited quickly through internet. The custom application developed by programmers can be easily extended, buyers only need to pay a small amount of money to use applications according to the service agreement without owning the software. Clearly, SaaS followed the trend of internet cloud computing technique and open platform. All in all, SaaS can offer custom various of infrastructures, software and hardware that required by information platform and enable small and medium users to use high speed internet more conveniently. It also come up with a novel approach to address the problems occurred in foundation pit informalization supervision.

\section{THE DESIGN OF OVERALL ARCHITECT}

As the core of platform construction, the overall architect of platform should satisfy the requirement of foundation surveillance and Technical Code for Monitoring of Building Excavation Engineering (GB 50497-2009) as well as rules of software development and design. Hence, the overall architect of platform is divided into IaaS, DaaS, PaaS, SaaS through bottom-up level and at the same time ensure the implementation of security, maintenance, standard norms and political rules in the platform architect, as shown in Figure 1. ${ }^{[6]}$

(1) IaaS mainly includes the resources of operation system, server, storage, network and security, which provide basic resource services such as calculation, storage, network and security for platform.

(2) DaaS mainly includes databases of information, project, device, developer, and experts, which met the design standard of database in Guidelines for Computer Software Product Development Documentation (GB/T 8567-2006) and national and industrial requirements. These databased designed 22 basic tables such as users table, message table, permission table, device table and prewarning value table. ${ }^{[7]}$

(3) PaaS provides platforms of the development, test and running of application, which has reserved space for function detention based on the original app platform, not only development cost is reduced but expansibility is improved.

(4) SaaS mainly offers services of data upload, calculation, analysis, prewarning and report generation. Company, project, developer, device and related data will be managed unitedly in Cloud, user can give instructions in cloud server (which will conduct the instructions immediately) and obtain data, report and information needed instantly through website and mobile phone. ${ }^{[8]}$

SaaS is constructed in technical-advanced and stable information cloud platform Ali Cloud. Apsara, as the flagship of Ali Cloud, is a hyperscale general computing operating system that developed independently by Ali Cloud and provide service globally. It can connect those mega servers located all over the world into a super computer and provide powerful, general and inclusive computing capacity in an online public service way. Neglecting the architecture of IaaS, DaaS and PaaS is available in Apsara, since the platform has concealed the fixing process of underlying fault and data redundancy, helped developer to manage data cluster and distributed program.

The cloud server ECS (Elastic Compute Service) constructed by Apsara is elastic and can serve all ranges of small and medium sized platform with efficient and low-cost cloud computing. Companies can choose appropriate ECS plan according to expected user scale and data size. The parameters of ECS basic plan is 4 vCPU, $16 \mathrm{GiB}$, Intel Xeon(Cascade Lake) Platinum $8269 \mathrm{CY}$ with $2.5 \mathrm{GHz} / 3.2 \mathrm{GHz}$, and the hardware specifications of it can be upgraded and expanded in real time if user had demanded. 


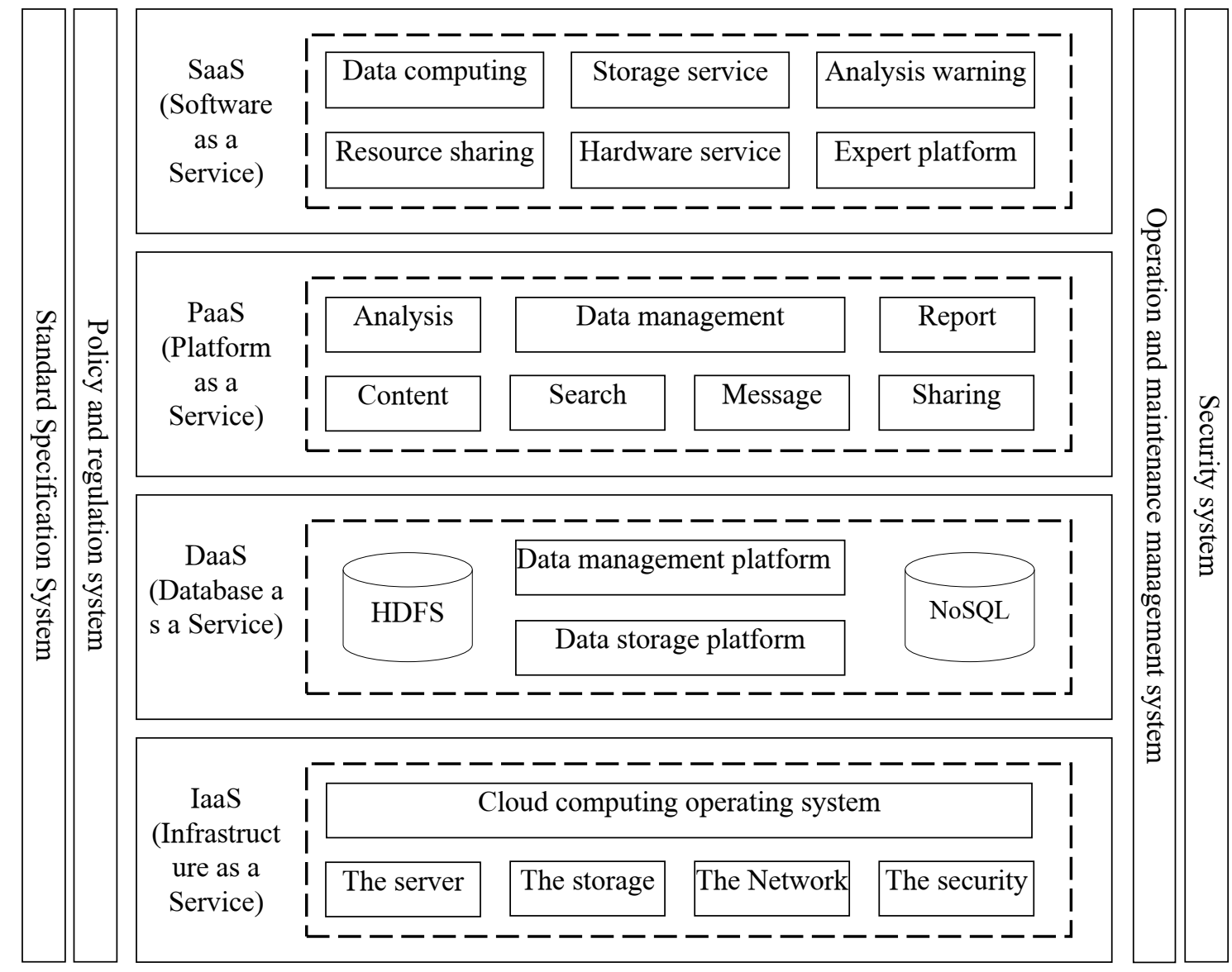

Fig. 1. The overall architecture.

\section{DESIGN OF CORE FUNCTIONS}

\subsection{User management}

The management and permission assignment of internal and external user (client, designer and supervisor involved in project) are the main function in this part. It enables businesses to add and delete internal user and staff who take part in the project. Internal users are allowed to receive and check messages, add and delete data and generate report while external users to subscribe information, check data and deal with prewarning message.

\subsection{Device management}

The main functions are adding and removing device, connecting and disconnecting device, uploading and downloading data, refreshing device and checking the monitoring. Such function is available in common brands and types of monitor device in market and interfaces for audio and video have been reserved.

\subsection{Prewarning management}

The key of prewarning lies in alarm threshold, which has conformed to the alarm value stated in Technical Code for Monitoring of Building Excavation Engineering
(GB 50497-2009) and users are allowed to apply it directly or make adjustment according to specific geology or designment. Once the supervised data is uploaded into platform, prewarning system will begin to calculate, analyze and decide whether it should give an alarm. The alarm will be given in form of curve table, result table and contact list and the alarm content will be sent to SMS, WeChat and email.

\subsection{Resource sharing}

The function of sharing is based on TCP/IP protocol which analyzed and compared datagram to ensure the stability and reliability of up and downlink of data. Enterprises can manage users, present data, analyze result, display page, feedback message, manage and download all kinds of report. If needed, the tables and reports that stored in platform or generated in real time can be shared to client, designer and supervisor.

\subsection{Expert management}

Two parts are included in this sector. The former one helps interaction and communication among administrator, user and expert via web or mobile phone while latter provides server, storage, and app of network security. The functions of it are schema optimization, transmission of real-time data, remote sharing of calculated data, calling service of platform and normalize database. 
The SaaS platform constructed on tech-advanced and reliable Ali Cloud provides the calculation and storage of monitored data, generation of report, prewarning analysis, sharing of resource and expert management with the requirement of foundation pit monitoring. Both efficiency and quality have been improved sharply and great technical support been given to the foundation pit informalization.

\section{CONCLUSIONS AND PROSPECTS}

The cloud platform of monitoring informalization SaaS is constructed on Ali Cloud, SaaS provides user services such as data calculation and analysis, early warning, and expert evaluation to realize the sharing of data and resources within the platform and improve the speed and reliability of monitoring. Now it has been applied successfully in some projects and honored with the Software Copyright Certificate (license number: 2019SR0608803) by National Copyright Administration of China and made great contribution to the economy and society. In the future, developers will take more consideration of users' feedback and strengthen research on visibility, BIM application, geotechnical engineering improvement and make the prewarning more precise, timely and informalization via big data and Cloud technology.

\section{ACKNOWLEDGMENTS}

This project is funded by High-Level Talent Project of Hainan Natural Science Foundation (SQ2019MSXM0462) and Provincial State-owned Capital Operation Project of Hainan Provincial Department of Finance in 2020(2020-01).

\section{References}

1. Elfatatry A., etc. Software as a Service: a negotiation perspective, Computer Software and Applications Conference, 2002. COMPSAC 2002. Proceedings. 26th Annual International, 501-506(2002)

2. Geng Liang. Risk management in SaaS platform development project[D], (2009)

3. Xie Chaoyang. Cloud Computing: planning, implementation, operation and maintenance[M], 131-171(2009)

4. Tang Sixin. Php web programming and Ajax technology[M], 254-322 (2017)

5. Zhai Yuehui. Design and implementation of enterprise management service platform based on SaaS Model[D],(2013)

6. Lin Dang. Design and implementation of mountain flood early warning information system in Yueyang City[D],(2014)

7. Bao Xin. Research and implementation of rainstorm and mountain flood disaster monitoring and early warning system[D],(2009)
8. Zhao Gang. Big data technology and Application Practice Guide[M], 55-56 (2013) 